\title{
ПОДХОДЫ К РАЗРАБОТКЕ ЭФФЕКТИВНОЙ СИСТЕМЫ КЛЮЧЕВЫХ ИНДИКАТОРОВ РИСКА
}

\author{
(C) 2021 Петров Александр Михайлович \\ доктор экономических наук, профессор Департамента бизнес-аналитики \\ Финансовый университет при Правительстве Российской Федерации, Россия, Москва \\ профессор кафедры бухгалтерского учета и налогообложения \\ Российский экономический университет им. Г. В. Плеханова, Россия, Москва \\ E-mail:palmi@inbox.ru
}

На сегодняшний день умелое управление рисками является составной частью показателя доходности коммерческой деятельности. Меняющаяся экономическая и геополитическая обстановка, нестабильность уровня спроса и предложения за счет различных факторов воздействия на них, высокая отраслевая конкуренция, опережающие темпы научно-технологического развития, резкие изменения валютных курсов, непостоянство законодательной базы и другие факторы создают условия, при которых возникает неопределенность деятельности экономического субъекта в получении ожидаемого конечного результата. Таким образом, большие транснациональные компании, международные холдинги и быстрорастущие субъекты хозяйствования применяют риск-ориентированный подход при определении долгосрочных стратегических целей. Но в переходной экономике Российской Федерации нестабильность текущей ситуации ведет к усложнению этой проблемы.

Ключевые слова: бюджетные нарушения, федеральный проект, отраслевой риск, ключевые индикаторы риска.

С целью преодоления неопределенности и прогнозирования вероятности от ущерба различных рисков, проводится анализ отраслевых рисков. Оценку отраслевых рисков осуществляют различные структуры, как предприниматели, так и сторонние субъекты хозяйствования (например, банковские структуры, инвестиционные компании, рыночные регуляторы и т.д.).

Внешнеотраслевые регуляторы определяют ключевые риски и выносят предписания о порядке действий в различных ситуациях. К примеру, в финансовой сфере таким внешним регулятором является Центральный Банк Российской Федерации. В прочих отраслях экономики внешними регуляторами являются министерства, которые оценивают риски и создают карты действий для участников рынка.

Оценкой рисков занимаются и сами экономические субъекты, такие как предприниматели или менеджмент крупных компаний. При управлении субъектом хозяйствования оценка отраслевых рисков крайне необходима для разработки долгосрочной стратегии поведения на рынке, определения возможностей и существующих угроз, оценки существенных рисков, требующих снижения.

В информации об отраслевых рисках за- интересованы профессиональные оценщики и различные информационные агентства, осуществляющие контроль за тем, что происходит в отрасли и объединяющие эту информацию в виде отраслевых аналитических отчетов.

Банковские структуры, оказывающие услуги по кредитованию физических и юридических лиц также сравнивают показатели по отрасли с показателями у кредитуемых. Таким образом, цель оценки отраслевого риска заключается в сохранении ресурсов субъекта хозяйствования или получении ожидаемого менеджментом дохода в результате выработанного решения.

Задачами системы управления отраслевыми рисками являются: выявление, сбор, обработка и хранение информации о внутренней и внешней среде; формирование системы факторов риска для экономического субъекта; определение угроз, выявленных факторами риска; выработка стратегии; разработка программы мероприятий по снижению уровня вероятности наступления угроз и иных инвестиционно-проектных мероприятий; ведения учета и отчетности по рисковым решениям.

Основным звеном рыночных отношений, а также их ключевым понятием является конкуренция. Конкуренция - это процесс управления 
субъектом собственными конкурентными преимуществами для переориентации на себя покупателя (или достижения других целей) в борьбе с конкурентами за удовлетворение объективных и/или субъективных потребностей в рамках законодательства [1]. Конкуренция является одной из основных черт рыночного хозяйства. Она является главным механизмом и ключевым средством контроля.

Конкуренция в экономике существует в разных формах и осуществляется различными методами. Она представляет собой естественный процесс сортировки лучших товаров для покупателей, установления ценового равновесия, зависимого от спроса на товары. Она проводит меры по «оздоровлению» субъектов экономической деятельности.

«Рынок - это:

1) место купли-продажи товаров и услуг, заключения торговых сделок;

2) экономические отношения, связанные с обменом товаров и услуг, в результате которых формируются спрос, предложение и цена» $[2,3]$.

«Отрасль - это совокупность организаций, предприятий, учреждений, производящих однородные товары и услуги, использующих однотипные технологии, удовлетворяющих близкие по природе потребности» [4].

Целью разработки системы ключевых индикаторов риска является выявление соответствующих показателей, предоставляющих необходимую информацию о потенциальных рисках, оказывающих влияние на достижение стратегических целей хозяйствующего субъекта.

Таким образом, разработка эффективной системы ключевых индикаторов риска начинается с анализа целей и рисков, влияющих на достижение тем самых целей. Взаимосвязь ключевых индикаторов риска позволяет выявить наиболее актуальную информацию, служащую в качестве индикатора, сигнализирующего о возникновении существенного риска. Связь стратегических задач с риском и ключевыми индикаторами риска проиллюстрирована на рисунке 1.

В соответствии с данными рисунка 1 , ключевые идентификаторы определяются для каждого угрожающего риска. Сопоставление ключевых идентификаторов с угрожающим риском позволяют менеджменту субъекта хозяйствования меньше отвлекаться на прочие сведения, являющиеся актуальными для достижения целей субъекта хозяйствования, и расставить правильные приоритеты.

Процесс выработки эффективной системы ключевых индикаторов риска начинается с анализа угрожающего события, негативно влияющего на субъект хозяйствования. Далее выявляются промежуточные и первичные события, предшествующие наступлению негативного события, которое влечет за собой существенный ущерб или упущенные возможности.

Основная задача данного процесса заключается в выработке индикаторов, предоставляющих объективную информацию о возможности осуществления угрожающего события. Чем ближе индикатор к источнику угрозы, тем выше вероятность того, что менеджмент субъекта хозяйствования предпримет необходимые действия, нивелирующие риск, для предотвращения наступления опасного события. Этот процесс отражен на рисунке 2.

На рисунке 2 проиллюстрирован процесс, в

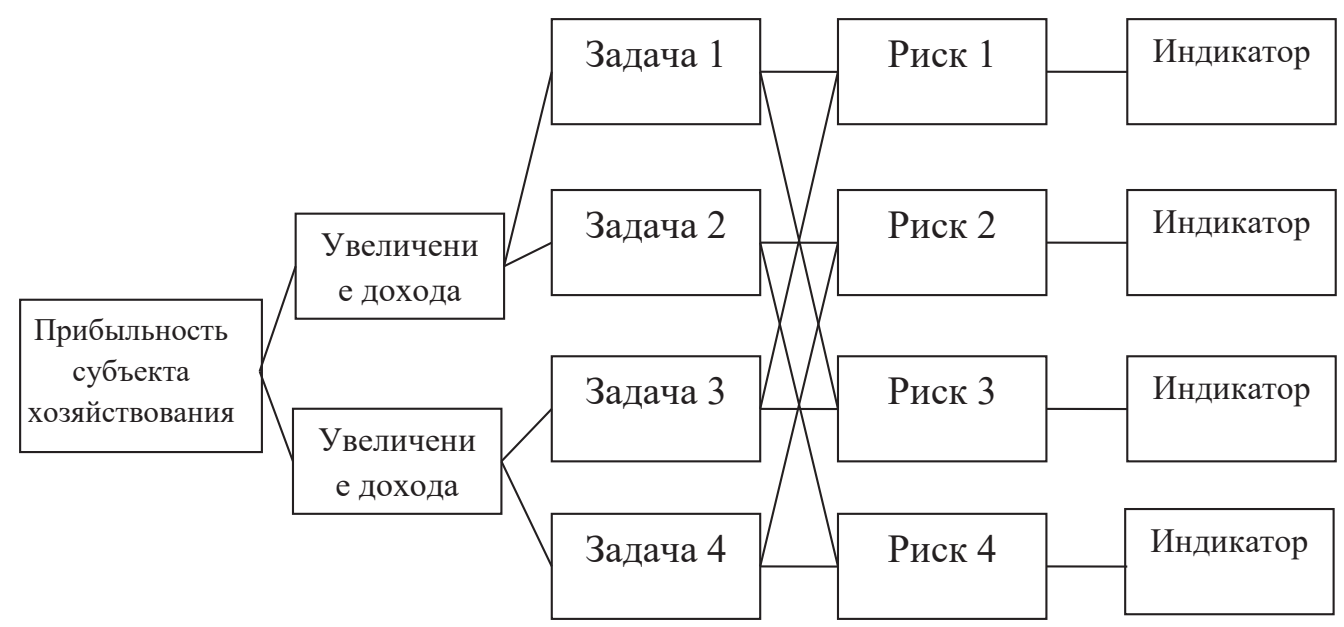

Рисунок 1. Иллюстрация системы ключевых индикаторов риска субъекта хозяйствования 


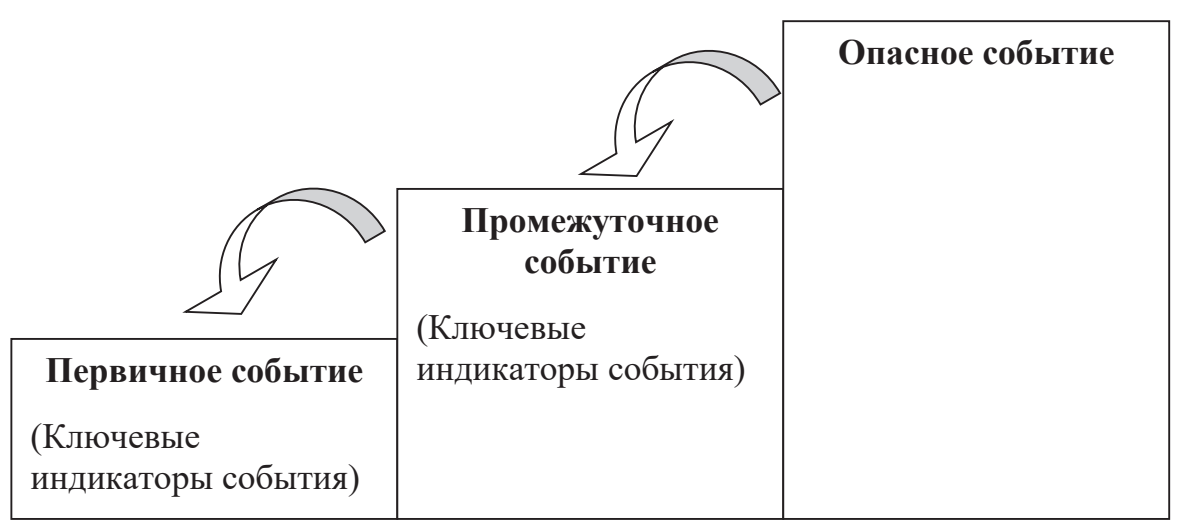

Рисунок 2. Процесс отбора ключевых индикаторов риска

котором выделяется причинно-следственная связь между событием, которое произошло, и причиной возникновения данного события. Разработка индикаторов помогает отследить всю цепь событий, которые приводят к угрозе, и предпринимать действия, нацеленные на нивелирование воздействия риска каждого этапа развития нежелательного события, которое угрожает возможности выполнения цели. Если менеджмент экономического субъекта имеет достаточное количество информации для определения ключевой причины, способной повлиять на возникновение нежелательного события, можно сделать вывод, что в таком случае менеджмент обладает рычагами воздействия на предотвращение негативных последствий.

\section{Библиографический список}

1. едеральный закон от 26.07.2006 N 135-Ф3 (ред. от 24.04.2020) «О защите конкуренции» // СПС КонсультантПлюс.

2. Прямая линия с Владимиром Путиным // Президент России: официальный сайт. - 2019. - 20 июня. Текст: электронный. - URL: http://kremlin.ru/events/president/news/60795.

3. Кузнецова О.Н. Методические подходы к оценке и управлению отраслевыми рисками // Российский внешнеэкономический вестник. - 2012. - № 10. - С. 106-116.

4. Райзберг, Б. А. Современный экономический словарь / Б. А. Райзберг, Л. Ш. Лозовский, Е. Б. Стародубцева. 6-е изд., перераб. и доп. - Москва: ИНФРА-М, 2017. - 512 с.

5. Петрова О.А. Проблемы развития рынка факторинговых услуг / - Экономические науки, № 9 (202), 2021. С. 232-234

6. Chernysheva N.A., Perskaya V.V., Petrov A.M., Bakulina A.A. Green energy for belt and road initiative: economic aspects today and in the future / International Journal of Energy Economics and Policy. 2019. T. 9. № 5. C. $178-185$.

7. Kevorkova Z.A., Petrov A. M., Savina N. V. TOWARDS LIABILITIES OF CORPORATE SYSTEMS / International Journal of Civil Engineering and Technology. 2019. T. 10. № 2. C. 1582-1593.

8. Petrov A.M., Nikiforova E. V., Kiseleva N.P., GrishkinaS.N., Lihtarova O. V. CREATION OF THE REPORTING ON SUSTAINABLE DEVELOPMENT OF COMPANIES BASED ON SOCIOECONOMIC MEASUREMENT STATISTICS / International Journal of Recent Technology and Engineering. 2019. T. 8. № 2. C. 4005-4012.

9. Sotnikova L.V., PolenovaS.N., Mislavskaya N.A., PetrovA.M., BasovaM.M. SUSTAINABLE DEVELOPMENT, MACRO AND MICRO LEVEL: RUSSIAN AND FOREIGN MODEL / International Journal of Recent Technology and Engineering. 2019. T. 8. № 2. C. 4524-4532.

10. Kosolapova M.V., Muravitskaya N.K., TolmachevM.N., Melnikova L.A., PetrovA.M. TECHNOLOGY FOR SOLVING THE PROBLEMS RELATED TO THE IMPLEMENTATION OF THE CONCEPT OF PRESERVING CAPITAL IN ACCOUNTING AND STATISTICS / International Journal of Recent Technology and Engineering. 2019. T. 8. № 3. C. 789-792.

11. Kosolapova M.V., PetrovA.M., YshanovI.G., MuravitskayaN.K., NurmuhamedovaH.S. THE ECONOMIC SIGNIFICANCE OF STATISTICAL RESEARCH ACTIVITIES OF REPRESENTATIVE OFFICES OF COMPANIES ABROAD / International Journal of Innovative Technology and Exploring Engineering. 2019. T. 8. № 10. C. 27132722 . 
12. Petrov A.M., Yurasova I.O., Putihin Y.E., Poluleh M.V., Erohina V.N. ACCOUNTANT MODELING TECHNOLOGY AND STATISTICS IN THE CONTEXT OF THE NEW EDUCATIONAL CONCEPT / International Journal of Innovative Technology and Exploring Engineering. 2019. T. 8. № 12. C. 3214-3217.

13. Petrov A.M., Kiseleva N.P., Kevorkova Z.A., Melnikova L.A., YshanovI.G. PRESENT DEVELOPMENT PRACTICES FOR TAX, FINANCIAL AND STATISTICAL REPORTING IN THE RUSSIAN FEDERATION / International Journal of Innovative Technology and Exploring Engineering. 2019. T. 8. № 12. C. 3538-3542.

14. Karpova T.P., Petrov A. M., Antonova O. V. DIRECTIONS OF ACCOUNTING DEVELOPMENT IN THE CONDITIONS OF DIGITALIZATION / Journal of Advanced Research in Dynamical and Control Systems. 2018. T. 10. № 7 Special Issue. C. $117-125$

15. Lymar M.P., Kevorkova Z. A., Petrov A. M. THE CONVERGENCE OF NATIONAL AND INTERNATIONAL ACCOUNTING STANDARDS: CHINESE EXPERIENCE / International Journal of Civil Engineering and Technology. 2018. T. 9. № 13. C. 82-94.

16. Бабаев Ю.А., Друцкая М. В., Кеворкова Ж. А., Листопад Е. Е., Петров А. М. БУХГАЛТЕРСКИЙ УЧЕТ, АНАЛИЗ И АУДИТ ВНЕШНЕЭКОНОМИЧЕСКОЙ ДЕЯТЕЛЬНОСТИ / учебник для студентов обучающихся по специальности 080109 «Бухгалтерский учет, анализ и аудит» / под редакцией Ю.А. Бабаева. Москва, 2010.

17. Петров А.М., ПоЛоУсЕ.А. ПОВЫШЕНИЕ ТРАНСПАРЕНТНОСТИ ПОКАЗАТЕЛЯ ДЕБИТОРСКОЙ ЗАДОЛЖЕННОСТИ В ОТЧЕТНОСТИ / Международный бухгалтерский учет. 2011. № 6 (156). С. 2-12.

18. Карпова Т.П., Петров А. М., Горбаткова Г. А., Самарина Л.Б., Дашкина Г. Г., Сидорова М. И., Сабанин Р. Л., Ситникова В. А., Листопад Е. Е. БУХГАЛТЕРСКИЙ УЧЕТ В СФЕРЕ УСЛУГ / учебник дЛя студентов высшего профессионального образования, обучающихся по специальности 080109 «Бухгалтерский учет, анализ и аудит» / Под редакцией М. А. Вахрушиной; Москва, 2011. Сер. Читай

19. Петров А.М., МеЛьнИковаЛ.А. ФОРМИРОВАНИЕ ОТЧЕТНОСТИ В СООТВЕТСТВИИ С ТРЕБОВАНИЯМИ МСФО КАК ОБЪЕКТИВНАЯ НЕОБХОДИМОСТЬ НА СОВРЕМЕННОМ ЭТАПЕ РАЗВИТИЯ ЭКОНОМИКИ РФ / Проблемы современной экономики. 2017. № 2 (62). С. 105-107.

20. ТЕОРИЯ БУХГАЛТЕРСКОГО УЧЕТА / учебник / Ю.А. Бабаев, А. М.Петров; под ред. Ю. А. Бабаева. Москва, Проспект, 2011. (Изд. 5-е, перераб. и доп.) 